\title{
Prospects for Electrification of Road Freight
}

\author{
Doros Nicolaides, Member, IEEE, David Cebon, and John Miles
}

\begin{abstract}
A plethora of decarbonisation pathways have been suggested over the last few years and it has been generally accepted that substantial progress towards more sustainable transport requires a significant contribution from the freight sector. Deep decarbonisation of road freight by conventional means is difficult, so alternatives need to be investigated. One of the most potentially beneficial approaches is electrification which is the subject of the paper. The challenges of conventional electric freight vehicles for long-haul operations are discussed and then innovative power delivery systems that could alleviate the problems are reviewed. A logistics concept to provide a framework for the electrification of most road freight transport operations is considered and based on that, simulation tools and methods are presented to set the performance requirements for a practical system. Finally, four case studies are developed for assessing the feasibility of electrification of various road freight operations. Overall, it is shown that electrification of road freight is a viable route for more sustainable transportation.
\end{abstract}

Index Terms - charge-on-the-move, dynamic charging, electric good vehicles, freight logistics, freight simulation

\section{NOMENCLATURE}

$\begin{array}{ll}\text { CoM } & \text { Charge-on-the-move } \\ \text { CSC } & \text { City Suburban Cycle } \\ \text { RDC } & \text { Regional Distribution Centre } \\ \text { DECC } & \text { Department of Energy and Climate Change } \\ \text { DfT } & \text { Department for Transport } \\ \text { EFV } & \text { Electric Freight Vehicle } \\ \text { ERCV } & \text { Electric Refuse Collection Vehicle } \\ \text { EV } & \text { Electric Vehicle } \\ \text { HGV10 } & \text { Heavy Good Vehicle 10 tonnes } \\ \text { HGV38 } & \text { Heavy Good Vehicle 38 tonnes } \\ \text { HWFET } & \text { Highway Fuel Economy Test } \\ \text { ICE } & \text { Internal Combustion Engine } \\ \text { IPT } & \text { Inductive Power Transfer } \\ \text { MECR }(\Psi) & \text { Mean Effective Charging Ratio } \\ \text { LDC } & \text { Local Distribution Centre } \\ \text { LGV } & \text { Light Good Vehicles 3.5 tonnes } \\ \text { Pr } & \text { Principal section of road } \\ \text { SOC } & \text { State of Charge of vehicle's battery } \\ \text { Tr } & \text { Trunk section of road } \\ \text { UCC } & \text { Urban Consolidation Centre } \\ \text { UDDS } & \text { Urban Dynamometer Driving Schedule }\end{array}$

Manuscript received:

D. Nicolaides is with the Department of Engineering, University of Cambridge UK (e-mail: $\underline{\text { dn314@ @am.ac.uk) }}$

\section{INTRODUCTION}

$\mathrm{T}$ he prospect of irreversible climate change has raised the obligation for governments to embark on substantial programmes of decarbonisation. Many possible pathways have been suggested over the last few years. It has been generally accepted that decarbonisation of the transport sector is a necessary step towards mitigating the effect of climate change.

The transport sector in the UK accounts for over a quarter of national $\mathrm{CO}_{2}$ emissions [1], 91.6\% of which are due to road transport [2]. According to [2], 17\% of road transport emissions emanate from light duty freight vehicles and $22 \%$ are from heavy good vehicles; the remainder are due to cars, passenger service vehicles, etc. Because the road freight sector is thought to be more difficult to decarbonise than personal transport, most decarbonisation strategies project that the proportion of total greenhouse gas emissions due to road freight will rise significantly in future. To this end, substantial progress towards more sustainable transport requires a significant contribution from the freight sector.

Decarbonisation strategies for the road freight sector can include a wide range of measures including improvements to aerodynamics and rolling resistance of lorries, lighter weight vehicles, improvements to propulsion efficiency, alternative fuels, higher capacity vehicles and operational factors such as reduced empty running, improved vehicle routing, etc. [3], [4].

Hydrogen is a possible alternative energy vector but the technology has been shown to be inappropriate for freight transportation. Widespread deployment of the required infrastructure and hydrogen storage are major barriers [5], [6]. Furthermore, the overall efficiency of a hydrogen generation and distribution system (production to wheels) is only $19-23 \%$ [7]. This poor overall efficiency is substantially lower than those of modern diesel engines, which are typically $40-45 \%$. Diesel engines therefore use about half as much energy overall as Hydrogen-powered electric vehicles [7], [8].

Another alternative to fossil fuels is biofuels. These require only limited investment in infrastructure and the performance of a vehicle powered by biofuels is similar to the performance of a conventional vehicle [6]. However, there is not sufficient biomass globally to replace more than $20 \%$ of the total vehicle fuel consumption, and even this would be at the expense of land for food crops being used for fuel [6]. The EU aims to have $10 \%$ of the transport fuel come from renewable sources such as biofuels by 2020 , with a corresponding reduction of the

D. Cebon is with the Department of Engineering, University of Cambridge UK (e-mail: dc@eng.cam.ac.uk)

J. Miles is with the Department of Engineering, University of Cambridge UK (e-mail: jcm91@eng.cam.ac.uk) 
greenhouse gas intensity of the EU fuel mix of 6\% [9]. There are no EU targets for higher levels of biofuel after 2020.

Natural gas can also be used for road freight vehicles. The technology has the potential for reducing $\mathrm{CO}_{2}$ emissions by 10$15 \%$. This is possibly a worthwhile interim measure, but it can never achieve the deep levels of decarbonisation needed in the long term. Again, there is insufficient biomethane for significant decarbonisation of freight transport on a national scale.

Hybrid drive trains are one possibility for making a significant difference. Odhams et al [3] showed that regenerative braking technologies could be capable of reducing fuel consumption of urban delivery vehicles by $25-30 \%$. Midgley et al [10], [11], [12] developed a hydraulic hybrid urban semitrailer to explore this option and demonstrated 9$18 \%$ reduction in fuel consumption depending on the drive cycle. Another vehicle concept suitable for urban freight deliveries was explored and then built as part of a European project [13].

Deep decarbonisation of road freight is challenging. One of the most potentially beneficial approaches is electrification, which is the subject of this paper. The necessary infrastructure for delivering electricity is sufficiently mature, although a significant upgrade would be required to accommodate the additional power demand of electrifying transport. Improved charging infrastructure would be needed, and this would be particularly challenging for long-haul freight. The adoption of electric freight transportation offers opportunities for zero emissions at the point of use, which is particularly attractive for urban areas. Yet there are still substantial $\mathrm{CO}_{2}$ emissions at the point of generation -the power plants. Consequently, shifting towards electric freight vehicles (EFVs) will only deliver significant $\mathrm{CO}_{2}$ reductions if the electricity supply network is decarbonised. For the UK, around $400 \mathrm{~g}$ of $\mathrm{CO}_{2}$ is emitted for every $\mathrm{kWh}$ of electricity generated [14]. According to national objectives this value has to be as low as $90-130 \mathrm{gCO}_{2} / \mathrm{kWh}$ by 2030 considering various possible decarbonisation scenarios and different emission rates through days and seasons. Even lower values are projected by 2040 around $30-50 \mathrm{gCO}_{2}$ per $\mathrm{kWh}$ [14]. If electrification is to be an effective measure for decarbonising road freight, almost complete decarbonisation of the electricity grid is a pre-requisite. This will have to be achieved in the face of significantly increased electricity demand for running transport systems, in addition to the conventional uses of electricity for light, heat and power.

Although the decarbonisation of transport sector is a longterm objective, electrification of freight transportation is also an interesting option for some nearer-term solutions. EFVs offer zero tailpipe emissions, eliminating the release of noxious pollutants. This feature coupled with low operating noise and straightforward implementation of regenerative braking make electric freight vehicles attractive for urban operations, particularly in cases where the required operating range is short and predictable. Examples are deliveries to city centre stores

\footnotetext{
${ }^{1}$ Battery recharging times can be over 8 hours whereas filling a liquid fuel tank requires only a few minutes. Though it might be argued that a number of
}

from urban consolidation centres (UCCs), e.g. the 'Regent Street UCC' operation in London [15].

Aspirations for electric urban deliveries are shared by some established freight companies and European funded projects. In particular, 'UPS' (package delivery company and provider of supply chain management solutions) has been investigating the adoption of alternative fuel engine vehicles for their operations. EFVs have been identified as an alternative that could significantly contribute towards the company's environmental objective to "deliver more while using less" [16]. The European 'ENCLOSE' project also aims to improve urban freight efficiency and advocates about the use of EFVs instead of conventional vehicles [17].

This paper aims to address the question of whether deep decarbonisation of the GB national road freight system by electrification is feasible. The analysis is focused on the case of GB which has been eager to adopt measures to reduce substantially its $\mathrm{CO}_{2}$ emissions by 2050 . Nevertheless, the methodology presented in the paper could be considered as a comprehensive framework to assess the prospects for electrification of road freight in other similar countries as well. Alternative national traffic statistics, road length data, drive cycle profiles, etc. could be processed by similar simulation tools and methods to those presented in the paper.

\section{A. Challenges}

Widespread penetration of EFVs is dependent on overcoming significant barriers. The largest of these are the high cost, mainly due to the batteries; the limited range; the long battery recharging times ${ }^{1}$ [18], [19], and the lack of public charging infrastructure [20]. Indeed, Lithium-Ion batteries, the most attractive technology for electric vehicle (EV) propulsion [21], have energy densities around $0.1 \mathrm{kWh} / \mathrm{kg}$, which is a an order of magnitude lower than for gasoline at $12 \mathrm{kWh} / \mathrm{Kg}$ [22]. This, coupled with the high power and energy demands of freight vehicles means that battery-power alone is not a practical proposition for long-haul freight transport. The only way to overcome this barrier would be to provide electricity to the vehicles while they are in motion.

\section{B. Power delivery/charging}

This section discusses the state of the art of power delivery/charging of electric vehicles (EVs), with the aim of identifying ways of overcoming the challenges and enabling the shift towards electric freight transportation. It reviews some current research into technical aspects of power delivery but it also highlights the lack of holistic research into the characteristics of charging systems.

Power charging systems for electric vehicles (EVs) have been under development for decades. Conductive systems are well established and have high efficiency and reliability. More recently, there has been considerable interest from academia and industry into non-conductive (wireless) chargers suitable for EVs [23]. The ability to avoid plug-in cables and to use simple systems that are unaffected by weather conditions is

fast recharging technologies have been proposed recently [53], there is no scientific consensus regarding battery degradation and reduction of life span. 
likely to be attractive to drivers.

The Inductive Power Transfer (IPT) technique is one of the most promising technologies for future power delivery. It has been used in numerous non-EV applications for over 25 years. These include entertainment systems of airplanes [24] where power is distributed wirelessly to video entertainment units set in the back of each passenger seat for convenience and maintenance reasons; harsh environments like underwater and mining applications [25], [26]; applications in factories such as cable-free power supplies for moving parts on machines [27]; clean rooms like semiconductors fabrication rooms [28]; lighting applications [29]; amusement parks; and others.

IPT involves contactless energy transfer between two LC circuits which are in proximity to each other. For example, in common transformers, energy is transferred between the primary and secondary coils through a magnetic field. Energy transfer efficiencies up to $98 \%$ can be achieved when there is strong magnetic coupling between the coils. In applications where a magnetic core cannot be used or the distance between the two circuits is large (tens of $\mathrm{mm}$ ), high efficiency can be obtained by tuning both circuits to a single resonant frequency.

A typical IPT system for EV power delivery applications is shown conceptually in Fig. 1. It comprises two major subsystems: the road charging unit (primary circuit) and the vehicle charging unit (pick-up or secondary circuit). The primary circuit is supplied with AC power at a suitable operating frequency. The transmitting coil is energised and the resulting magnetic flux is captured by the vehicle charging unit, inducing an $\mathrm{AC}$ voltage which can be rectified to produce a stable DC power source for the electric motor, the batteries and other loads on board. Compensation is required on both sides of the system to minimise the reactive impedance of the system and maximise the power transfer delivery.

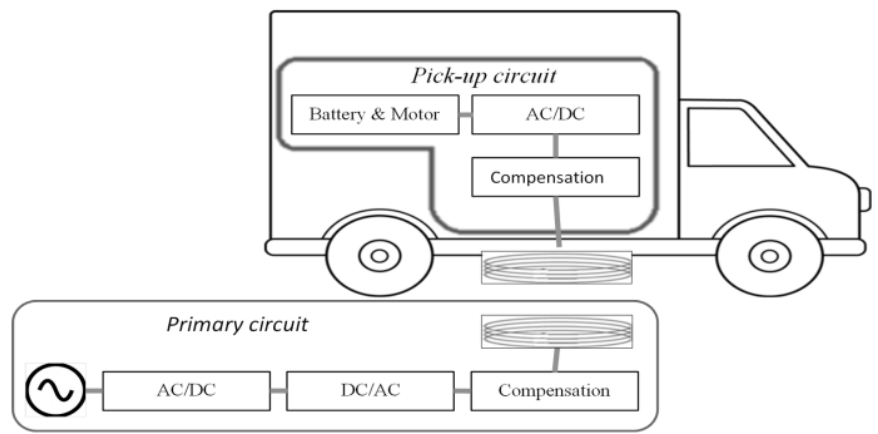

Fig. 1. Typical IPT system for EFVs power delivery

Development of IPT devices would enable 'charge-on-themove' (CoM) also known as 'dynamic charging' to be implemented. In such a system, the road infrastructure would transfer energy wirelessly to road vehicles whilst they are on move. This technology offers the opportunities for substantially reducing the installed battery capacity of EVs, eliminating 'range anxiety', reducing the cost and mass which are some of the major barriers for widespread use of EVs.

Previous theoretical work on the subject revealed that CoM technology is technically and economically feasible for passenger cars [30], [31]. The total cost of installing CoM infrastructure on the GB's motorway and Rural ' $\mathrm{A}$ ' road network was estimated to be $£ 3 \mathrm{~m}$ and $£ 2.6 \mathrm{~m}$ per mile of road respectively; a cost that is similar to that required for electrifying one mile of train track at $£ 2-4 \mathrm{~m}$. Such a charging infrastructure would enable the electrification of up to $86 \%$ of passenger car-miles, excluding those travelled on urban roads, for less than $£ 80 \mathrm{~b}$ which is similar to the cost of building the HS2 rail link between London and Birmingham [30]. The social and environmental aspects of CoM in the GB have been assessed using sustainability principles [32]. Overall, it was concluded that CoM could play a significant role as part of the $\mathrm{CO}_{2}$ mitigation efforts in the future without undermining social integrity, environmental stability, or economic prosperity.

Only limited number of experimental CoM systems have been tested in practice and the performance of such a system cannot been specified accurately at the moment. However, the IPT technology for the automotive industry has been under development for some years. High efficiencies for static charging applications around 95\% can be achieved in power delivery of tenths $\mathrm{kW}$ across hundreds of millimetres of air gap with some misalignments [33], [34], [35]. Moreover, ongoing research aims to maintain similar levels of efficiency for dynamic charging applications [36], [37]. This coupled with likely widespread penetration of lane keeping assistance driving aids for eliminating misalignment issues, the efficiency of potential CoM systems is expected to reach up to $90 \%$.

A comprehensive study of battery degradation and life in relation to CoM, has not been found in the literature. Nevertheless, it has been reported frequent, small charging boosts (as may be provided by a CoM infrastructure) would increase the life of Lithium-Ion batteries when compared with deep charging and discharging cycles [38].

The 'charge-on-the-stop' concept involves installation of IPT devices at pre-determined locations along a well pre-defined route, for charging commercial EVs during their journeys. Such an approach could be used for buses that charge at stops or at terminals; urban freight vehicles that charge at depots and delivery points; or even refuse collection vehicles which could charge at stopping points along their routes. One such example is the Milton Keynes bus project [39], in which electric buses receive a $10 \mathrm{~min}$ booster charge at wireless charging points locate at either end of a $25 \mathrm{~km}$ route between the Milton Keynes suburbs of Wolverton and Bletchley. The line carries an estimated 800,000 passengers a year.

Overhead catenary systems provide an alternative technology for charging EFVs on the move. Similar technology has been use for years for powering trams, trains, and trolley buses, but has recently been applied to electric road freight vehicles. Siemens has been developing a catenary system for electric lorries since 2011 as part of the ENUBA research project [40]. The diesel-electric hybrid trucks collect electrical energy from overhead wires, using a sophisticated pantograph system that can connect and disconnect autonomously as the vehicle enters and exits electrified sections of road (Fig. 2). The energy supply consists of a two-wire overhead system, operating at around $650 \mathrm{VDC}$, with current ratings that match the characteristics of the $260 \mathrm{~kW}$ electric motors on the vehicles. 


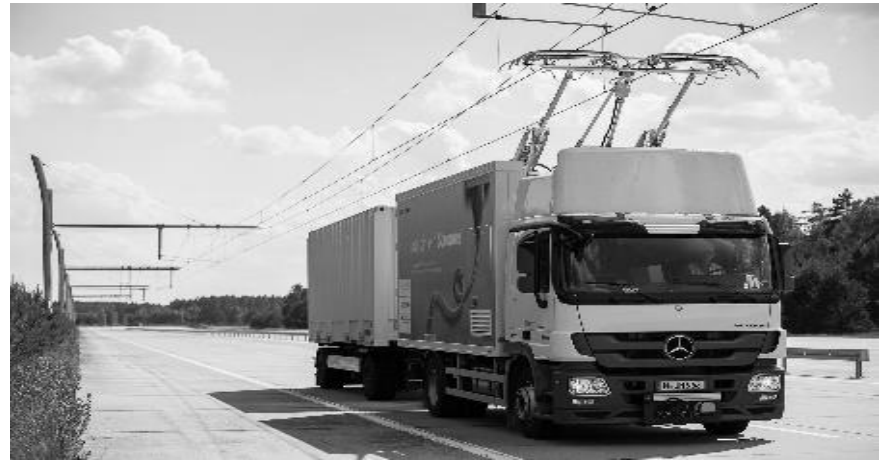

Fig. 2. Siemens overhead catenary system, from [40]

Either of these 'electrified highway' systems could potentially provide power to future long haul highway vehicles.

\section{LOGISTICS CONCEPT AND OPPORTUNITIES}

It is very unlikely that existing long-haul road freight vehicles could be converted to battery-powered electric freight operation, because of their high power consumption, long distances travelled, large amounts of energy required and the relatively low energy-density of existing and foreseeable future battery technologies. It would be impractical (and too expensive) to carry sufficient batteries. However, with utilisation of CoM technologies, electrified long-haul freight may be possible. This would necessitate some changes to the logistics network to enable appropriate electrification strategies to be used in the various types of operation. This section defines a modified structure of logistics network that would facilitate such a change. Fig. 3 presents a concept for overall road freight operations in GB that could potentially be used in conjunction with current and likely future electrification technologies to provide a framework for the electrification of most road freight transportation operations.

In this model, road freight transportation is divided into four main categories: 'long-haul trunking', 'urban delivery', 'home delivery', and other 'auxiliary services'. Different vehicles and charging infrastructures would be needed for each of these operations.

(i) 'Long-haul trunking' is responsible for the transportation of goods between national and regional distribution centres (RDCs) and local distribution centres (LDCs) or Urban Consolidation Centres (UCCs), on the edges of cities using the national trunking network. Most journeys are travelled on motorways and principal roads by heavy good vehicles of 35-44 tonnes gross mass. In an electrified freight system, these trunk routes would have CoM infrastructure. These vehicles would therefore only need modest battery capacity to handle short off-network operations, in and out of depots.

(ii) 'Urban delivery' refers to deliveries within city boundaries and the supply of goods from LDCs (which could be located at supermarkets) to inner-city convenience stores, or from UCCs to individual shops. Heavy good vehicles up to 10 tonnes would be mainly exploited for this type of services. The journeys would be fairly short and predictable, and mostly take place on major urban roads. Such operations could be operated by battery-powered EVs that charge their batteries while loading at depots and could potentially top-up at wireless charging points while unloading - e.g. at convenience stores.

(iii) Transportation of goods from LDCs to consumers would be performed by 'home delivery' operations, using light good vehicles, often under 3.5 tonnes. These could be battery EVs that are routed for multi-drop operations within their available electric range.

(iv) 'Auxiliary services' includes other operations within the area of municipalities, such as refuse collection functions, buses, etc. Such vehicles could use 'charge-on-the-stop' technologies, with contactless 'top-up' charging points distributed at key locations along their routes. This would significantly reduce the necessary battery capacity.

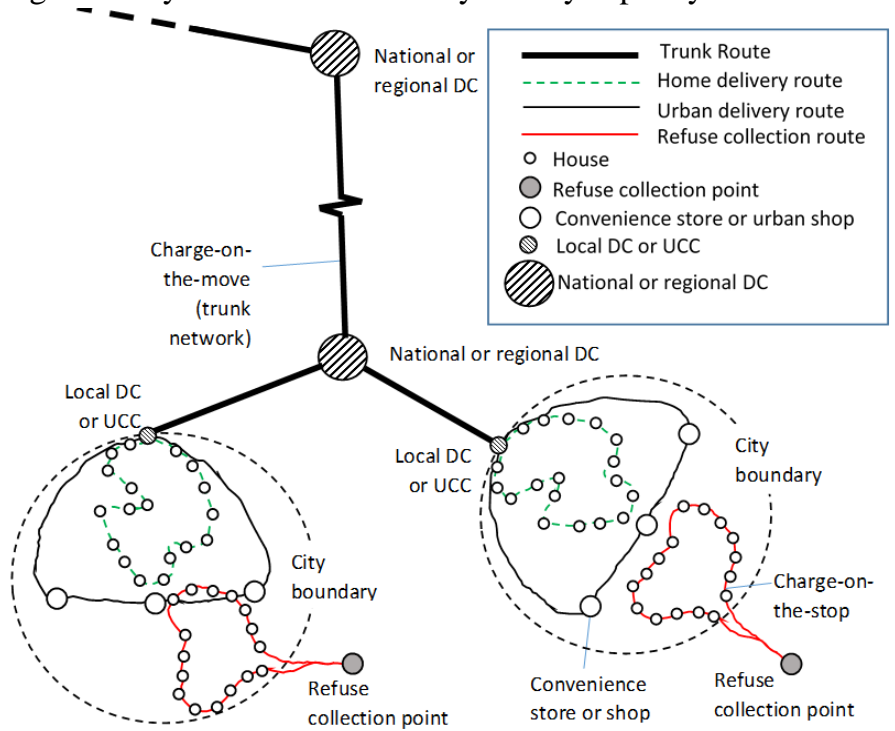

Fig. 3: Logistics concept for electrified road freight. Not to scale.

It is unlikely that all freight operations could utilize this system. There are some other types of operation such as deliveries of large in-divisible loads or transport of fuels and hazardous liquids where this approach would not be viable. However, these operations could use 'plug-in hybrid' propulsion systems. This would enable them to use the CoM infrastructure for fully-electric, long-haul operations, but with an internal combustion engine (ICE) to charge the batteries and provide an extended range when operating off the CoM network. These operations off the network could likely be done at relatively low speeds and would therefore require less power than high-speed long haul trunking. Consequently, the ICE could be significantly smaller than the large diesel engines in existing heavy vehicles and the $\mathrm{CO}_{2}$ emissions of these residual hybrid operations would be much lower. These vehicles are not considered further in this paper.

Our selection of the particular electrification system for each of the logistics operations is based on using the smallest possible battery pack in each case. This would reduce the weight, cost, embodied energy and rolling resistance of the vehicle and allow more mass and volume for the payload. Where charging can be performed practically during the journey, to enable use of a smaller battery (e.g. charging while loading or unloading), this is the chosen option. 


\section{ModELLING}

Based on the logistics concept described above, system performance requirements can be defined and the various aspects of the freight system can be simulated to assess their feasibility for electrical operations. This is the approach taken in this paper.

A simulation is firstly performed to estimate the average power requirements of EFVs. Then, the derived figures are combined with GB road traffic data to get an estimate of the anticipated power demands on various roads around the country. Finally, a charging simulation tool is presented to illustrate how the provision of dynamic charging could be used by long-haul freight vehicles to investigate important parameters such as mileage range and state of charge (SOC) of the vehicle's battery.

\section{A. System characterisation}

The 'Advanced Vehicle Simulator' (Advisor) was used to estimate the power requirements of EFVs travelling on specified driving cycles. Advisor is an open source software tool that was developed at the National Renewable Energy Laboratory for the US Department of Energy in 1994 [41]. The latest version of the software was released in 2003. Its accuracy has been validated by several authors and international labs [42], [43].

A substantial list of standard vehicle models is available, including light and heavy-duty vehicles with conventional, hybrid-electric, and full-electric powertrain configurations. In order to model the performance, fuel economy, and emissions of a particular vehicle, the user specifies components such as motors, batteries, vehicle mass, additional electric loads etc. The simulations are executed over selected driving cycles, containing speed and elevation profiles versus time (or distance). The Advisor database has been supplemented by driving cycles for urban, rural, and motorway roads appropriate for freight vehicles as described by [44]. The driving cycles are differentiated by vehicle type: light good vehicles (up to $3,500 \mathrm{~kg}$ ) and heavy good vehicles (over 7,500kg) as illustrated in Fig. 4 and Fig. 5 respectively.

The simulation produces a variety of output quantities. For EFVs these include the target and actual speeds of the vehicle through the driving cycle, the power required from the electric motor, and the battery SOC versus time/distance.

Three different categories of EFVs are considered in this paper, based on the logistics concept described above. These are: (a) light good vehicles up to 3.5 tonnes (LGV); (b) heavy good vehicles up to 10 tonnes (HGV10); and (c) heavy good vehicles up to 38 tonnes (HGV38). Standard vehicles provided by Advisor were adjusted appropriately and values were determined for the power rating of electric motors, the capacities of the on-board batteries, constant electrical loads (e.g. for refrigeration), and the overall masses of the vehicles. The final values are summarised in TABLE 1 .

Advisor was used to determine the average power requirements for each category of EFV. The 'LDV_PVU 3.5t vans motorway', 'LDV_PVU 3.5t vans rural', and 'LDC_PVU $3.5 \mathrm{t}$ vans urban' drive cycles, as shown in Fig. 4 , were used for
LGVs travelling on motorways, rural, and urban roads respectively. Similarly, the 'Highway Fuel Economy Test (HWFET)', 'EPA Urban Dynamometer Driving Schedule (UDDS)', and 'City Suburban Cycle (CSC)', as shown in Fig. 5, were used for both HVG10 and HGV38 vehicles. The results are presented in TABLE 2 for three different road types. For example, an electric LGV demands an average power of $40 \mathrm{~kW}$, $18 \mathrm{~kW}$, and $11 \mathrm{~kW}$ on motorways, rural, and urban roads.

TABLE 1

COMPONENTS OF SIMULATED EFVS

\begin{tabular}{cccccc}
\hline \hline & Advisor's vehicle model & $\begin{array}{c}\text { Motor } \\
(\mathrm{kW})\end{array}$ & $\begin{array}{c}\text { Battery } \\
(\mathrm{kWh})\end{array}$ & $\begin{array}{c}\text { Load } \\
(\mathrm{kW})\end{array}$ & $\begin{array}{c}\text { Mass } \\
(\mathrm{kg})\end{array}$ \\
\hline LGV & Full size cargo van & 75 & 27 & 2 & 3,500 \\
HGV10 & Ralphs Grocery 1998 & 75 & 42 & 4 & 10,000 \\
HGV38 & Kenworth T800 Trailer & 277 & 85 & 4 & 38,000 \\
\hline \hline
\end{tabular}

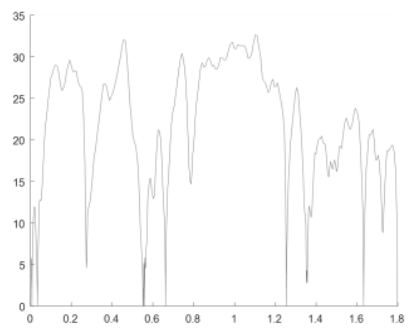

(a)

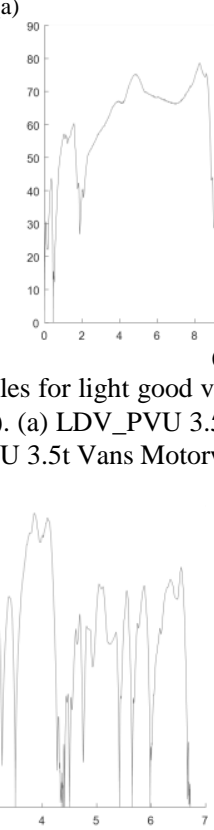

(a)

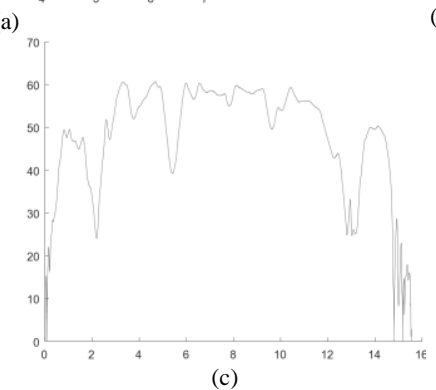

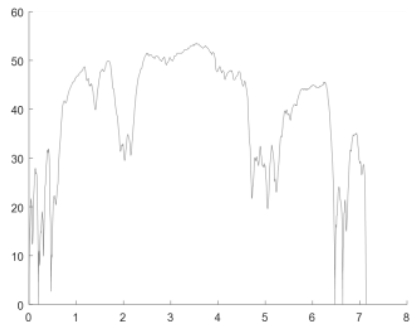

(b)
Fig. 4. Driving cycles for light good vehicles used in this study - Speed (mph) vs Distance (miles). (a) LDV_PVU 3.5t Vans Urban (b) LDV_PVU 3.5t Vans Rural (c) LDV_PVU 3.5t Vans Motorway
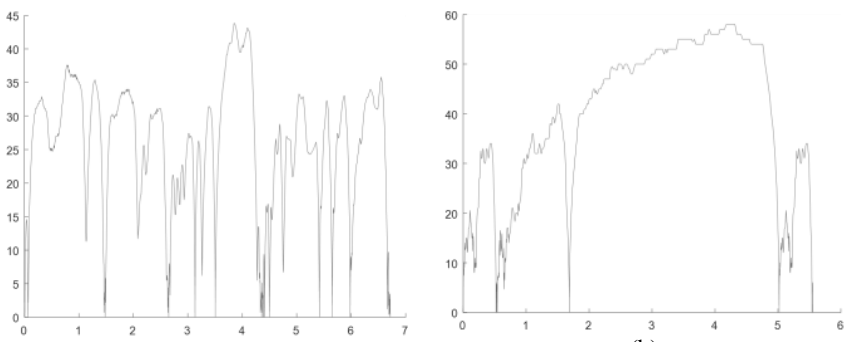

b)
Fig. 5. Driving cycles for heavy good vehicles used in this study - Speed (mph) vs Distance (miles). (a) City Suburban Cycle (CSC) (b) EPA Urban Dynamometer Driving Schedule (UDDS) (c) Highway Fuel Economy Test (HWFET) 
TABLE 2

AVERAGE POWER REQUIREMENTS - KW PER MILE OF ROAD

\begin{tabular}{lccc}
\hline \hline & Motorway $(\mathrm{kW})$ & Rural 'A' (kW) & Urban (kW) \\
\hline LGV & 40 & 18 & 11 \\
HGV10 & 61 & 38 & 25 \\
HGV38 & 123 & 100 & 74 \\
\hline
\end{tabular}

These average power requirements were combined with the numbers of EFVs on various roads, in order to estimate the total power needed from the power infrastructure. Average annual daily traffic flow by road class was obtained from Department for Transport (DfT) statistics for various types of vehicles. The base data [45] provides the number of vehicles per day that will drive on a specific stretch of road on an average day of the year. Various road freight vehicle classes merged together into three main categories. Category 1 contains vehicles up to and including 3.5 tonnes. Category 2 contains vehicles from 3.5-19 tonnes. Category 3 contains vehicles in the 19-44 tonnes range. The three categories were selected appropriately to match both the vehicles considered in the logistics concept (Fig. 3) and the three modelled EFVs (LGV, HGV10, and HGV38).

The number of vehicles per mile of road for each category was estimated for each region of GB by dividing the average daily traffic by 24 (hours of the day) and the appropriate speed limits for each section of road. Practical speed limits in GB for LGV up to 3.5 tonnes are (i) $70 \mathrm{mph}$ travelling on motorways (ii) $50 \mathrm{mph}$ on rural 'A' roads and (iii) $30 \mathrm{mph}$ on urban roads. For HGV over 7.5 tonnes the assumed speed limits are (i) $56 \mathrm{mph}$ travelling on motorways (ii) $50 \mathrm{mph}$ on rural roads, and (iii) $30 \mathrm{mph}$ for urban roads. TABLE 3 , TABLE 4 , and TABLE 5 present the average number of vehicles per mile of road in GB for the three categories of freight vehicles. The derived figures, which include $30 \%$ safety margin, present data for all major roads in GB classified into trunk ( $\mathrm{Tr}$ ) and principal (Pr) sections ${ }^{2}$.

TABLE 3

CATEGORY 1 VEHICLES PER MILE OF ROAD IN GB BY REGION IN 2013 (AVERAGE NUMBER THROUGH A DAY)

\begin{tabular}{llcccccc}
\hline \hline & \multicolumn{3}{c}{ Motorway } & \multicolumn{2}{c}{ Rural 'A' } & \multicolumn{2}{c}{ Urban 'A' } \\
& & $\operatorname{Tr}$ & $\operatorname{Pr}$ & $\operatorname{Tr}$ & $\operatorname{Pr}$ & $\operatorname{Tr}$ & $\operatorname{Pr}$ \\
\hline England & North East & 6 & 6 & 3 & 1 & 14 & 4 \\
& North West & 8 & 4 & 2 & 1 & 6 & 4 \\
& Yorkshire-Humber & 8 & 6 & 4 & 1 & 10 & 4 \\
& East Midlands & 10 & 0 & 4 & 1 & 9 & 4 \\
& West Midlands & 8 & 8 & 3 & 1 & 11 & 4 \\
& East of England & 10 & 0 & 5 & 2 & 8 & 4 \\
& London & 11 & 0 & 0 & 4 & 0 & 6 \\
& South East & 10 & 6 & 5 & 2 & 8 & 4 \\
Wales & South West & 7 & 0 & 3 & 1 & 8 & 4 \\
Scotland & & 7 & 0 & 2 & 1 & 7 & 4 \\
\hline \hline
\end{tabular}

TABLE 4

CATEGORY 2 VEHICLES PER MILE OF ROAD IN GB BY REGION IN 2013 (AVERAGE NUMBER THROUGH A DAY)

\begin{tabular}{llcccccc}
\hline \hline & & \multicolumn{3}{c}{ Motorway } & \multicolumn{2}{c}{ Rural 'A' } & \multicolumn{2}{c}{ Urban 'A' } \\
& & $\operatorname{Tr}$ & $\operatorname{Pr}$ & $\operatorname{Tr}$ & $\operatorname{Pr}$ & $\operatorname{Tr}$ & $\operatorname{Pr}$ \\
\hline England & North East & 1 & 1 & 1 & 0 & 2 & 0 \\
& North West & 2 & 1 & 0 & 0 & 1 & 0 \\
& Yorkshire-Humber & 2 & 1 & 1 & 0 & 2 & 0 \\
& East Midlands & 2 & 0 & 1 & 0 & 1 & 0
\end{tabular}

\footnotetext{
${ }^{2}$ A trunk road in GB is a major road (motorway) between places of traffic importance. The entire trunk road network (Primary Route Network) has the aim to provide easily identifiable routes to access the whole of the country [54].
}

West Midlands

East of England

London

South East

South West

Wales

Scotland

\begin{tabular}{llllll}
2 & 1 & 1 & 0 & 2 & 0 \\
2 & 0 & 1 & 0 & 1 & 0 \\
2 & 0 & 0 & 1 & 0 & 1 \\
2 & 1 & 1 & 0 & 1 & 0 \\
2 & 0 & 1 & 0 & 1 & 0 \\
1 & 0 & 0 & 0 & 1 & 0 \\
1 & 0 & 0 & 0 & 2 & 0 \\
\hline
\end{tabular}

TABLE 5

CATEGORY 3 VEHICLES PER MILE OF ROAD IN GB BY REGION IN 2013 (AVERAGE NUMBER THROUGH A DAY)

\begin{tabular}{llcccccc}
\hline \hline & & \multicolumn{3}{c}{ Motorway } & \multicolumn{2}{c}{ Rural 'A' } & \multicolumn{2}{c}{ Urban 'A' } \\
& & $\operatorname{Tr}$ & $\operatorname{Pr}$ & $\operatorname{Tr}$ & $\operatorname{Pr}$ & $\operatorname{Tr}$ & $\operatorname{Pr}$ \\
\hline England & North East & 4 & 1 & 2 & 0 & 4 & 0 \\
& North West & 7 & 1 & 1 & 0 & 1 & 0 \\
& Yorkshire-Humber & 8 & 1 & 3 & 0 & 5 & 0 \\
& East Midlands & 11 & 0 & 4 & 0 & 3 & 0 \\
& West Midlands & 8 & 2 & 2 & 0 & 4 & 1 \\
& East of England & 8 & 0 & 3 & 0 & 4 & 0 \\
& London & 8 & 0 & 0 & 1 & 0 & 1 \\
& South East & 6 & 1 & 2 & 0 & 2 & 0 \\
Wales & South West & 5 & 0 & 1 & 0 & 2 & 0 \\
Scotland & & 4 & 0 & 0 & 0 & 1 & 0 \\
\hline \hline
\end{tabular}

The average number of vehicles per mile of road across a day were shaped with daily traffic distribution data obtained from DfT [46]. The derived daily profiles were combined with the power requirements listed in TABLE 2 to calculate the power demand per mile of road across GB throughout a typical day. The methodology assumes 100\% adoption of EFVs for sizing the infrastructure, based on current traffic conditions.

Although Category 1 (LGVs) and Category 2 (HGV10) vehicles are not supplied in-motion but on-the-stop according to the logistics concept in section II, we can still estimate the additional power demand based on the number of vehicles per mile of road. We assume that the number of LGVs/HGV10 on the roads of $\mathrm{GB}$, given by Table $3 / 4$, is the same, with LGVs/HGV10 performing urban/home delivery operations. The required energy to be supplied to the vehicles (i) continuously from a CoM infrastructure or (ii) at intervals from charge-on-the-stop top-up points, must be the same. The power demand is calculated in hourly steps. Hence, the average power within a 1-hour time slot is the same for both situations. Although the actual power demand varies within the 1-hour time slot, our study does not investigate smaller time resolution.

As an illustration, the average density of LGVs per mile of motorway in London is presented with the dashed line in Fig. 6 ; whereas the average power required to propel this number of vehicles during each hour of the day is presented with the solid line. During the peak hours of the day, the average power demand by LGVs is around $920 \mathrm{~kW}$ per mile of motorway. The average power required per mile of motorway in London for HGV10 and HGV38 during the peak hours is $260 \mathrm{~kW}$ and $1,790 \mathrm{~kW}$ respectively. The average power required to electrify the road freight transportation for each type of major road and different regions of GB can be calculated. The peak power demands are summarised in TABLE 6. Notice that a total

The remaining sections of major roads in GB (A-Roads) are classified as Principal roads. 
additional power demand of $9.4 \mathrm{GW}$ during the peak hours would be introduced to the electricity grid. The magnitude of the load exceeds substantially the capacity margin of the electricity supply network in GB at peak hours, which is around $5 \mathrm{GW}$ [47].

Nevertheless, various authorities have already embarked on plans to upgrade the electricity supply network around the country, because the power demand is estimated to increase significantly in future due to the shifting to EVs and electric heating. To this end, the anticipated installed generating capacity in GB is estimated to be around $100-130$ GW by 2050 which is approximately double the current installed capacity [48]; giving a significant capacity margin for the electrification of road freight. Furthermore, the Electricity Networks Strategy Group has defined pathways to reinforce the transmission network of GB [49] and finally, various distribution companies have already embarked on upgrade projects to deal with the increased future demand [50], [51].

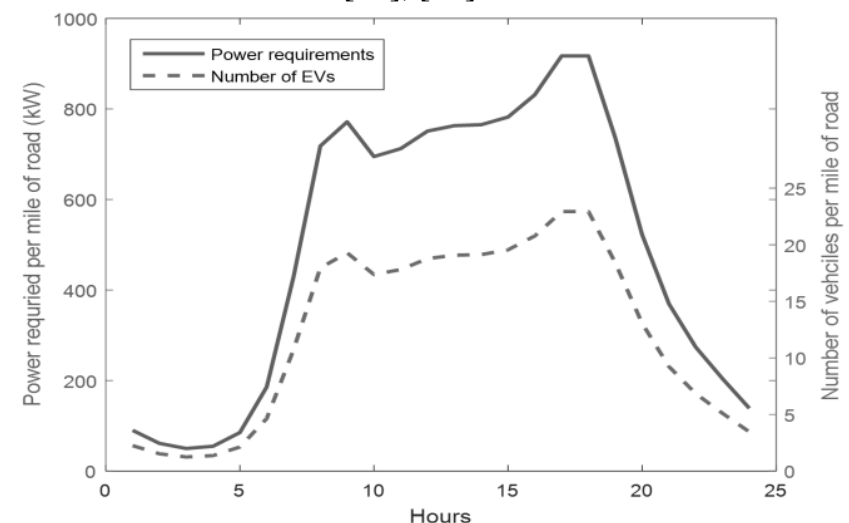

Fig. 6. Power required and density of LGV on a typical motorway in London by hour of day

TABLE 6

PEAK POWER DEMAND IN GW OF ELECTRIFIED ROAD FREIGHT TRANSPORTATION

\begin{tabular}{lcccc}
\hline \hline & Motorway & Rural 'A' & Urban 'A' & Total \\
England & 4.8 & 2.8 & 0.6 & 8.2 \\
Wales & 0.1 & 0.2 & 0.04 & 0.3 \\
Scotland & 0.4 & 0.4 & 0.08 & 0.9 \\
Total & $\mathbf{5 . 3}$ & $\mathbf{3 . 4}$ & $\mathbf{0 . 7}$ & $\mathbf{9 . 4}$ \\
\hline \hline
\end{tabular}

\section{B. Charging Simulation tool}

A simulation tool was developed on top of the 'Advisor' software tool to investigate the application of dynamic charging and the effects of system design variables on important performance parameters, such as the mileage range and the SOC.

The input interface to the tool is shown in Fig. 7. The inputs are:

(i) The type of EFV and its driving cycle;

(ii) The specification of the EFV's batteries: cell capacity, number of cells in parallel, number of modules in series, initial SOC;

(iii) The specifications of the dynamic charging system: distance between consecutive chargers, the charging segment length, and the nominal power rating of the charger.

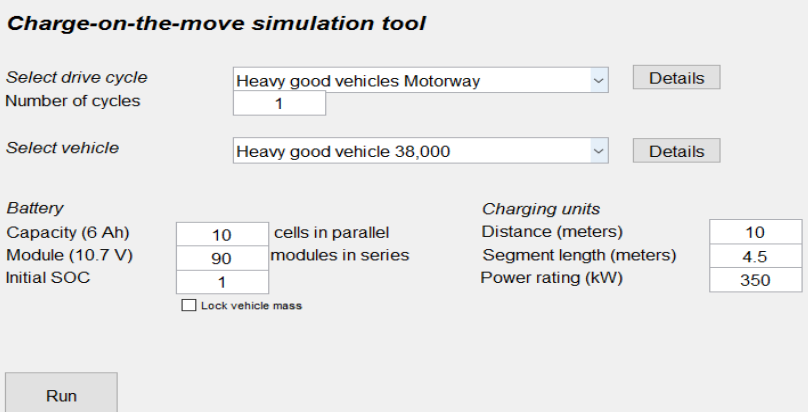

Fig. 7. Charging simulation tool input interface

The example in Fig. 7 shows the input data for investigating the journey of a HGV38 vehicle travelling on motorway, $45 \%$ of which is 'online' $(4.5 \mathrm{~m}$ segment/ $10 \mathrm{~m}$ apart) at $350 \mathrm{~kW}$ nominal power transfer rate.

The charging model assumes instantaneous operation of chargers when a vehicle is located within the charging segment length boundaries and 100\% energy transfer efficiency without considering any misalignments between the vehicle and the charging device. In practice some inefficiency (typically 90\%) is expected, as explained in the introduction for real CoM systems. Any tolerance on fore-aft misalignment is assumed to be included in the segment.

Fig. 8 shows the results of a simulation based on the input data in Fig. 7. The four graphs show: (a) the requested (target) speed of the vehicle during the run; (b) the power required from the electric motor to track the drive cycle; (c) the energy requested (used), the energy received, and the energy consumed throughout the whole journey; and (d) the SOC of the vehicle with and without the use of the CoM system. At the bottom of the figure additional outputs of the run are listed: (i) the battery capacity of the vehicle under investigation, (ii) the final SOC without any charging facilities, (iii) the final SOC with CoM infrastructure, (iv) the total energy requested (used by the electric motor) in the simulation run, (v) the energy received from the CoM system, (vi) the energy consumed during the whole journey, (vii) the equivalent fuel economy of the vehicle under investigation, (viii) the average consumption of the vehicle, and finally (ix) the 'Mean Effective Charging Rate' (MECR), denoted $\Psi$, which is the energy delivered by the charging system per metre along the road.

The speed, power, and energy are calculated by the 'Advisor' simulation according to the parameters of the vehicle and driving cycle under investigation. The energy received from the charging system and the consequent SOC of the vehicle are determined by the charging simulation and depend on the user's input specification for the charging system. The longer the charging segments and the power rating, the larger the amount of energy transferred; whereas the greater the distance between two segments, the lower SOC at the end of the journey.

It can be seen from the third graph of Fig. 8 that the energy 'requested' (used) by the electric motor is relatively constant during the journey, whereas the energy received, and as a result, the energy consumed (which is plotted with negative values when the energy received is greater than the energy requested), fluctuate between zero and a relatively constant value. This is 
due to the fact that charging devices are installed periodically along the road and energy is transferred only when the vehicle is located over the charging device. The upper value of transferred energy is influenced by the power rating of the charging device and the speed of the vehicle; since the longer the charging coil spends within the effective boundaries of the charging system, the higher the received energy.

Finally, the fourth graph in Fig. 8 shows that HGV38 would have $33 \%$ SOC on battery power alone after 16 miles on this driving cycle, whereas with a dynamic charging system capable of delivering $\Psi=9.3 \mathrm{~kJ} / \mathrm{m}$, it could run indefinitely.

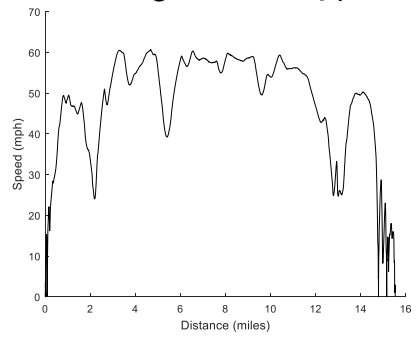

(a)

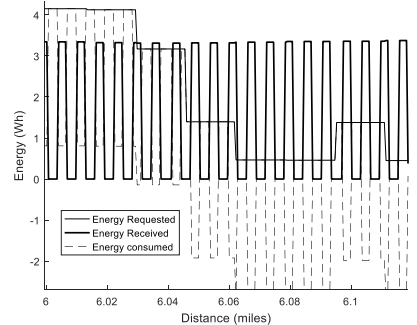

(c)

Battery

Capacity $(\mathrm{kWh})$

Final SOC (\%)

Final SOC with

CoM (\%)

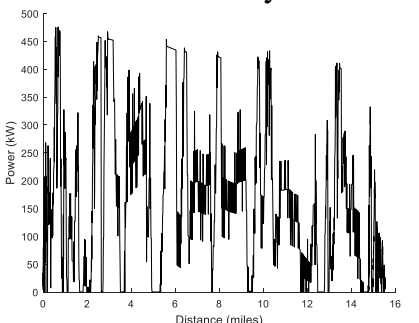

(b)

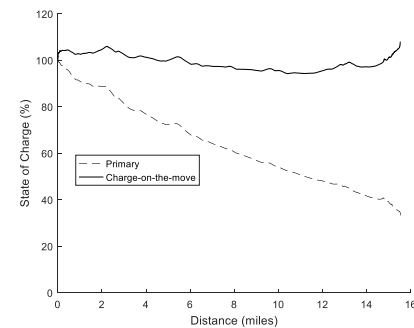

(d)

Equivalent fuel $\quad 8.2$ economy (mpg) Aver. consum. $(\mathrm{kWh} / \mathrm{mile})$ $\Psi(\mathrm{kJ} / \mathrm{m}): 9$

Energy Received (kWh)

110 Energy Consumed $(\mathrm{kWh})$

Fig. 8. Output of a simulation for HGV38 travelling on the HWFET drive cycle, shown in Fig. 5c. (a) Requested speed of vehicle (b) Requested power from electric motor (c) Energy plots (d) State of charge history

\section{CASE STUdies}

This section develops four case studies for assessing the feasibility of electrification of road freight.

\section{A. Long haul}

The first case study is concerned with 'long-haul freight transport' which enables the transportation of goods between distribution centres located on or near to trunk routes. Articulated heavy vehicles in the range 33-44 tonnes are mainly used for this type of deliveries in Europe and our analysis assumes the HGV38 articulated vehicle described in TABLE 1. In the simulation, each vehicle is assumed to have a $277 \mathrm{~kW}$ electric motor, $85 \mathrm{kWh}$ battery capacity, $4 \mathrm{~kW}$ constant consumption for on-board loads, and 38 tonnes overall mass.

In the logistics model shown in Fig. 3, long-haul journeys are assumed to occur predominantly on trunk routes, with just a few miles of local roads between highway exits and the delivery points (distribution centres). To this end, the investigation for

\footnotetext{
${ }^{3}$ The average speed of the vehicle following the HFET drive cycle, shown in Fig. $5 \mathrm{c}$ is $34 \mathrm{mph}$. The power required then is calculated as $P=$ $9.3 \mathrm{~kJ} \times 34 \mathrm{mph}=140 \mathrm{~kW}$
}

long-haul deliveries is divided in two parts: (i) the trunk roads themselves, where a CoM system must be provided to enable steady-state operation, with the on-board batteries running at a constant (or increasing) state of charge; (ii) the journey from the end of each trunk road to nearby delivery points / distribution centres and back to the motorway, using battery power.

\section{1) Driving on Trunk Roads}

The charging simulation tool was used to determine the MECR level $\Psi$ needed to balance out the energy consumed by the vehicle on a motorway, using the Highway Fuel Economy Test (HFET) drive cycle, shown in Fig. 5c. Fig. 9 shows the SOC of the HG38 vehicle model, for various MECR values $\Psi$. For $\Psi=0$, no energy is transferred to the vehicle and it can be seen that the SOC is depleted rapidly after approximately 22 miles $(35 \mathrm{~km})$ journey on a motorway. When $\Psi=8.2 \mathrm{~kJ} / \mathrm{m}$ the energy received from the dynamic charging system largely balances the energy consumed by the vehicle and the SOC remains around $100 \%$ throughout the whole trip. For $\Psi=$ $9.3 \mathrm{~kJ} / \mathrm{m}$, the vehicle receives more energy, on average, than it uses in motorway driving and the final SOC for these conditions is around $10 \%$ more than the initial SOC.

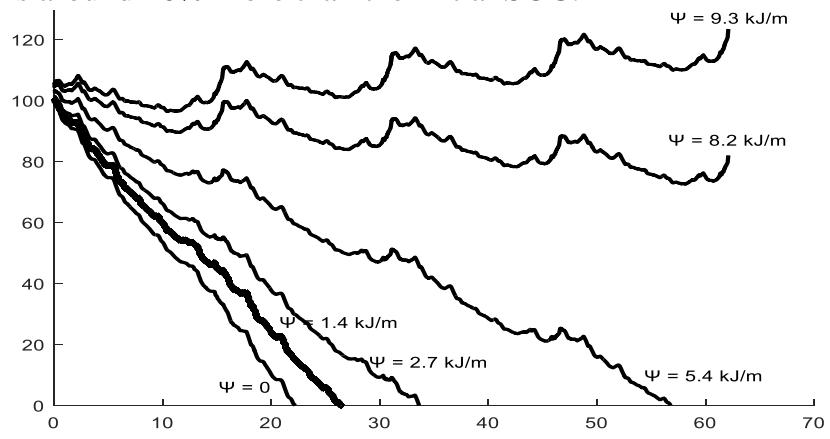

Fig. 9. Long-haul SOC of HGV38 for various levels of MECR

Both overhead catenary systems and IPT devices could be exploited to deliver $9.3 \mathrm{~kJ} / \mathrm{m}$ or alternatively $140 \mathrm{~kW}^{3}$.

Many of the practical challenges of overhead catenary systems are well understood, but there are still some technical and operational issues that would need to be resolved:

(i) The catenary system would not be suitable for cars - so the infrastructure and operating costs would have to be borne by the freight industry alone;

(ii) High voltage wires carried above the roadway might pose a significant threat to safety, in the event of a collision between a vehicle and a roadside support pole.

(iii) Maintenance of exposed wiring located above the carriageway would be challenging.

IPTs would eliminate all the above-mentioned issues but they have their own drawbacks when compared with overhead catenary systems:

(i) No IPT device with a power transfer rating over $50 \mathrm{~kW}$ is commercially available. This is significantly lower than the required power transfer rating for the road freight transport application. Even with $100 \%$ coverage of the road surface, a power of $140 \mathrm{~kW}$ is needed, which is approximately three times 
higher than any existing device. However, it would be possible to have multiple pick-up devices underneath each truck, each of which could receive power from a single transmitter. So if 3 or 4 receivers could be fitted under each tractor unit, the transmitters would each need to deliver $46 \mathrm{~kW}$ or $35 \mathrm{~kW}$ respectively, which is reasonable, and thought to be achievable.

(ii) Installation of the charging devices would require digging-up much of the existing motorway network - at least in the 'slow lane', where HGVs mostly travel.

(iii) The installation would have to be durable, long lasting and not cause excessive surface roughness. This would not be straightforward for asphalt pavements, which are prone to crack around devices mounted in the surface.

(iv) There may be human health issues associated with the high magnetic fields generated by the charging system. Research is needed to ensure that the human exposure is maintained within acceptable, safe limits.

(v) Ideally, heavy good vehicles, light good vehicles, and passenger cars would be able to use the same IPT infrastructure. This would improve the prospect of a privately financed system for distributing the large amounts of energy involved. The business case for this needs clarification.

\section{2) Driving on Local Roads}

This section considers the energy used by the heavy goods vehicle driving on the local roads at the ends of each motorway segment. The driving cycle is assumed to be a combination of two consecutive UDDS driving profile shown in Fig. 5b. The long-haul vehicle (HGV38) is assumed to exit the motorway with $100 \%$ SOC, travel up to 5.5 miles to the delivery point under battery power and return to the motorway. As shown in Fig. 10, this can be achieved with a safety margin of $36 \%$ SOC. Once the vehicle re-enters the motorway, the CoM infrastructure will recharge the on-board battery during the subsequent highway driving. Optionally, the vehicle could be partially re-charged during the delivery process, using fixed IPT devices located appropriately at each loading bay in the destination centre.

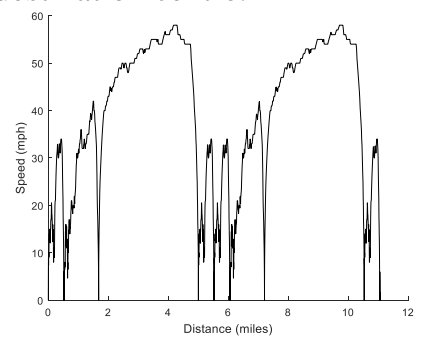

Battery $\quad 86 \quad$ Energy Requested

Final SOC $(\%) \quad 36 \quad \begin{aligned} & \text { Energy } \\ & (\mathrm{kWh})\end{aligned}$ $\begin{array}{lll}\text { Capacity }(\mathrm{kWh}) & 86 & \begin{array}{l}(\mathrm{kWh}) \\ \text { Energy Received }\end{array}\end{array}$

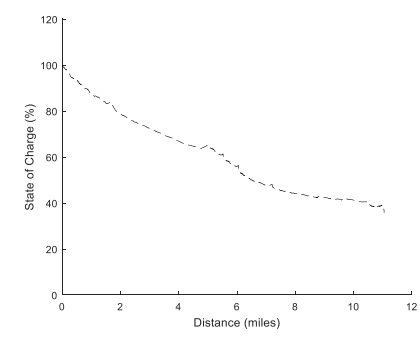

55 Equivalent fuel Aver. consum. (kWh/mile) economy (mpg) 5.8

Fig. 10. Output of a simulation for HGV38 travelling on local roads for longhaul operations (a) Requested speed of vehicle (b) State of charge history

This case study has shown that shifting towards electrification of long-haul deliveries is not an unreasonable proposal, provided the logistics infrastructure could be changed to the configuration shown in Fig. 3. This kind of operation could be undertaken by purely electric HGVs with $85 \mathrm{kWh}$ of on-board batteries - which is a practical size.

Using the 'Advisor' model the fuel economy of a 38 tonnes diesel-powered lorry was calculated to be 6.5 miles per US gallon when travelling the overall long-haul delivery trip (including driving both on trunk and local roads). About $10.2 \mathrm{kgCO}_{2}$ are produced from burning a gallon of diesel fuel [52]. As a result, a conventional 38 tonne vehicle emits around $1.6 \mathrm{kgCO}_{2} / \mathrm{mile}$. The $\mathrm{HGV} 38$ model consumes an average of $4 \mathrm{kWh} /$ mile on the same combined drive cycle on trunk and local roads for the long-haul delivery trip. Using the carbon intensity of the UK electricity supply network in 2016 of approximately $400 \mathrm{gCO}_{2} / \mathrm{kWh}$ [14], this corresponds to approximately $1.6 \mathrm{kgCO}_{2} / \mathrm{mile}-$ similar to that of the diesel vehicle. However, using DECC's projected $\mathrm{CO}_{2}$ intensity of 90 $130 \mathrm{gCO}_{2} / \mathrm{kWh}$ [14] for the significantly decarbonised UK electricity grid in 2030, the $\mathrm{CO}_{2}$ emissions of the 38 tonnes vehicle would be only $360-520 \mathrm{gCO}_{2} / \mathrm{mile}$. This corresponds to a very significant reduction of $68-78 \%$. Using DECC's projected $\mathrm{CO}_{2}$ intensity of $30-50 \mathrm{gCO}_{2} / \mathrm{kWh}$ in 2040 , reduction of $88-93 \% \mathrm{CO}_{2}$ emissions is feasible. This highlights the fact that variations of $\mathrm{CO} 2$ intensity of the grid with time are a second order effect compared to the average. TABLE 7 shows an overview of the Long Haul delivery case study.

TABLE 7

LONG HAUL CASE STUDY OVERVIEW

Solution

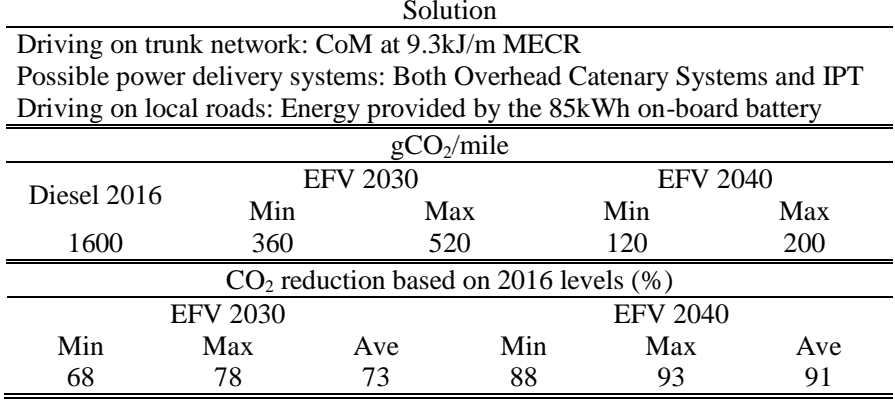

\section{B. Urban delivery}

Under the logistics scenarios shown in Fig. 3, urban delivery vehicles would transport goods between LDCs and UCCs, on the edge of cities to convenience stores and urban shops. HGV10 is assumed to be the backbone of such urban deliveries. A typical journey is assumed to have two delivery points on an 18 mile round-trip, driven on major regional and urban roads. The assumed driving cycle is illustrated in Fig. 11a. It consists of a combination of a rural driving cycle (CSC in Fig. 5a), followed by an urban driving cycle (UDDS in Fig. 5b) and then a repeat of the rural driving cycle. The vehicle is assumed to have the components shown in TABLE 1 , with a $75 \mathrm{~kW}$ electric motor, $42 \mathrm{kWh}$ battery, $4 \mathrm{~kW}$ constant on-board load (e.g. refrigerator), and 10 tonnes overall mass.

The results of the simulation are illustrated in Fig. 11. It is apparent that this urban delivery journey could be undertaken by an entirely electric 10 tonnes heavy good vehicle equipped with a $42 \mathrm{kWh}$ battery. The vehicle would commence its journey with $100 \%$ SOC and return to the starting point after the 18 mile round trip with $24 \%$ SOC.

Another option is that the vehicles could be charged en-route, in order to maintain continuous operation. Taking advantage of the fact that such urban deliveries could probably take place on 
pre-determined routes with known delivery points, a 'chargeon-the-stop' approach could be used, whereby the EFVs would charge statically at the delivery points.

The MECR level $\Psi$ needed to balance out the energy consumed by the vehicle is $\Psi=4.3 \mathrm{~kJ} / \mathrm{m}$. Over the 18 mile journey, this would correspond to an accumulated energy of about $125 \mathrm{MJ}(35 \mathrm{kWh})$. Assuming that a static charging station is located at the main distribution centre and at the two delivery points, the three charging stations would each need to deliver around $12 \mathrm{kWh}$ of energy to the vehicle's battery in order to maintain $100 \%$ SOC. This could be achieved using $50 \mathrm{~kW}$ chargers, running for $15 \mathrm{~min}$ on average while the vehicle is stopped during each loading and unloading process. This appears to be reasonably practical and would allow consecutive urban deliveries.

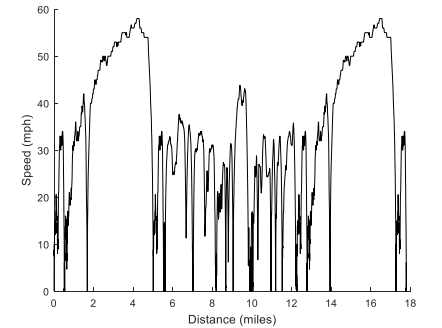

Battery $\quad 42 \quad$ Energy Requested Capacity (kWh) $42 \quad(\mathrm{kWh})$

Final SOC (\%) $24 \quad \begin{aligned} & \text { Energy Received } \\ & (\mathrm{kWh})\end{aligned}$

Fig. 11. Results of Urban delivery journey for HGV10 (a) Requested speed of vehicle (b) State of charge history

The average $\mathrm{CO}_{2}$ emissions of a conventional ten tonnes diesel vehicle is around $680 \mathrm{gCO}_{2} /$ mile based on the computed equivalent fuel economy of $16.5 \mathrm{mpg}$. The average energy of HGV10 is $1.7 \mathrm{kWh} / \mathrm{mile}$ on this drive cycle (Fig. 11a). Assuming $400 \mathrm{gCO}_{2} / \mathrm{kWh}$ for the electricity grid (2016 levels) [14], this corresponds to $680 \mathrm{~g} \mathrm{CO}_{2} /$ mile - again, similar to the conventional diesel. Assuming a decarbonized grid with 90$130 \mathrm{gCO}_{2} / \mathrm{kWh}$ (2030 levels) [14], the impact would be 153$221 \mathrm{gCO}_{2} /$ mile (not too different to a good mid-size car in 2016). Again this corresponds to at about $68-78 \%$ reduction of $\mathrm{CO}_{2}$ emissions in comparison with urban operations by conventional vehicles. Similarly, reduction of $88-93 \% \mathrm{CO}_{2}$ emissions by 2040 is feasible. TABLE 8 shows an overview of the Urban Delivery case study. The $\mathrm{CO}_{2}$ reduction data follows the same pattern as the previous case study (lower part of TABLE 7).

TABLE 8

URBAN DELIVERY CASE STUDY OVERVIEW

\begin{tabular}{ccccc}
\hline \multicolumn{5}{c}{ Solution } \\
\hline \multicolumn{5}{c}{ Charge-on-the-stop at delivery points } \\
15 minutes charging boost at 50kW power transfer \\
\hline \hline \multicolumn{5}{c}{$\mathrm{gCO}_{2} / \mathrm{mile}$} \\
\hline \multirow{2}{*}{ Diesel 2016} & $\mathrm{Min}$ & $\mathrm{MFV} 2030$ & $\mathrm{Min}$ & $\mathrm{MFV} 2040$ \\
680 & 153 & 221 & 51 & 85 \\
\hline \hline
\end{tabular}

\section{Home delivery}

The prospects for electrification of home delivery are discussed in this part of the paper. Under the assumed logistics system in Fig. 3, home delivery operations would transport goods from LDCs and city-edge supermarkets to consumers.
Light good vehicles up to 3.5 tonnes are mostly used for this task today. The electric versions of today's delivery vans ('LGV') are assumed to be equipped with a $75 \mathrm{~kW}$ electric motor, $27 \mathrm{kWh}$ battery, and a $2 \mathrm{~kW}$ refrigerator, as stated in TABLE 1. A typical home delivery journey might have 10 delivery points on urban roads, as it is shown in Fig. 12a. The assumed driving profile is a combination of a rural driving cycle (Fig. 4b) followed by ten consecutive urban delivery cycles (Fig. 4a), completed with another rural driving cycle.

The results of the simulation are illustrated in Fig. 12. The vehicle leaves the depot with $100 \%$ SOC and returns back with a safety margin of $26 \%$ SOC after consuming $20 \mathrm{kWh}$ of energy. This means that an hour charging boost, using a $20 \mathrm{~kW}$ charging station (or $30 \mathrm{mins}$ at $40 \mathrm{~kW}$ ) during the loading process at the LDC would be sufficient to fully charge the battery before each delivery trip.
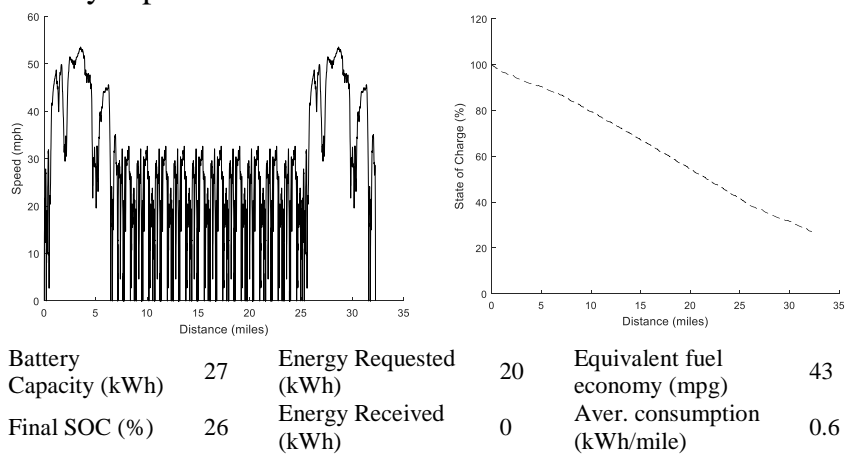

Fig. 12. Results of Home delivery journey for LGV (a) Requested speed of vehicle (b) State of charge history

Using the calculated average energy consumption of $0.6 \mathrm{kWh} / \mathrm{mile}$ (Fig. 12), and the same assumptions as before for the carbon content of the electricity grid, this would correspond to $240 \mathrm{gCO}_{2} /$ mile in 2016 and $54-78 \mathrm{gCO}_{2} /$ mile in 2030 and 18 $30 \mathrm{gCO}_{2} /$ mile in 2040, based on [14]. Again this corresponds to a reduction of at $68-78 \%$ by 2030 and $88-93 \%$ by 2040 compared to today's conventional diesel van which was calculated to emit $240 \mathrm{gCO}_{2} /$ mile for the same drive cycle. The $\mathrm{CO}_{2}$ reduction data follows the same pattern as the previous case studies. TABLE 9 shows an overview of the Home Delivery case study. The $\mathrm{CO}_{2}$ reduction data follows the same pattern as the previous case studies.

TABLE 9

HOME DELIVERY CASE STUDY OVERVIEW

\begin{tabular}{ccccc}
\hline \hline \multicolumn{5}{c}{ Solution } \\
\hline \multicolumn{5}{c}{ Charge-on-the-stop at LDC } \\
30 minutes charging boost at 40kW power transfer \\
\hline \hline \multicolumn{5}{c}{$\mathrm{gCO}_{2} /$ mile } \\
\hline Diesel 2016 & Min & Max & Min & EFV 2040 \\
240 & 54 & 78 & 18 & 30 \\
\hline \hline
\end{tabular}

\section{Refuse collection}

For the final case study, we explore the possibility of shifting to electric refuse collection vehicles (ERCVs). Refuse collection vehicles need power for the bin-lifters, refuse compaction, for lighting indicators, and various other systems on board. Furthermore, an ERCV with an overall mass around 27 tonnes (8 tonnes unladed mass plus 19 tonnes carrying 
capacity) has to undertake many rapid accelerations and decelerations using energy from the battery on board, but, ideally, also benefitting from regenerative braking technology.

A typical refuse collection driving profile is illustrated in Fig. 13a. The driving profile is based on the 'William H. Martin Refuse Hauler Drive Cycle' provided by 'Advisor' but the cycle was modified to increase the number of stops to approximately 62 within 6.5 miles in a 1.7 hours shift. The drive cycle includes driving from the depot to the collection area and back to the origin. The vehicle under investigation is equipped with a $147 \mathrm{~kW}$ electric motor, a $32 \mathrm{kWh}$ battery and it has 27 tonnes overall mass, which is the fully-loaded mass to provide a worst case scenario. Furthermore, the vehicle has $2 \mathrm{~kW}$ constant load for on-board equipment including load for the bin lifting and compaction system.

The results of the simulation are illustrated in Fig. 13. The vehicle leaves the depot with 100\% SOC and returns back with a safety margin of $20 \%$ SOC after consuming $25 \mathrm{kWh}$ of energy. This means that a $30 \mathrm{~min}$ charging boost, using a $50 \mathrm{~kW}$ charging station during the un-loading process would be sufficient to fully charge the battery before each refuse collection trip. However, effective functionality of the charging stations might be compromised by the harsh environment of the refuse collection sites. To this end, wireless IPT charging devices could be distributed at key locations along the route. In particular, 10 'top-up' charging points at $50 \mathrm{~kW}$ each would be sufficient to maintain continuous operation of ERCV s provided the vehicle is stationary for about $3 \mathrm{~min}$ for charging during bin lifting or compaction procedures.
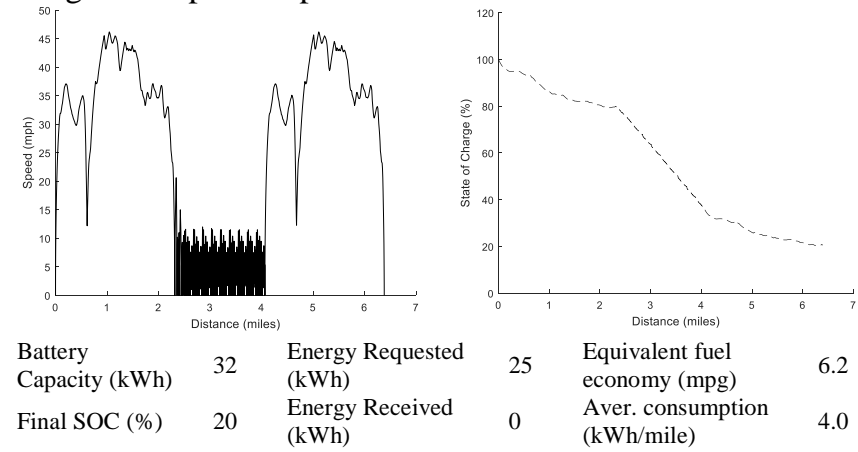

Fig. 13. Results of Refuse Collection trip (a) Requested speed of vehicle (b) State of charge history

The average $\mathrm{CO}_{2}$ emissions of a conventional 27 tonnes diesel vehicle is around $1.65 \mathrm{kgCO}_{2} /$ mile based on the computed equivalent fuel economy of $6.2 \mathrm{mpg}$. The average energy of $\mathrm{ERCV}$ is $4.0 \mathrm{kWh} / \mathrm{mile}$ on this drive cycle (Fig. 13a). Assuming $400 \mathrm{gCO}_{2} / \mathrm{kWh}$ for the electricity grid (2016 levels), this corresponds to $1.6 \mathrm{kgCO}_{2} / \mathrm{mile}$ - again, similar to the conventional diesel. Assuming a decarbonized grid with 90$130 \mathrm{gCO}_{2} / \mathrm{kWh}$ in 2030 levels), the impact would be 360 $520 \mathrm{gCO}_{2} /$ mile. Again this corresponds to $69-75 \%$ reduction of $\mathrm{CO}_{2}$ emissions in comparison with refuse collection functions by conventional vehicles. Similarly, reduction of $88-93 \% \mathrm{CO} 2$ emissions is feasible using the DECC's projected figures for 2040 levels. TABLE 10 shows an overview of the Home Delivery case study. The $\mathrm{CO}_{2}$ reduction data follows the same pattern as the previous case studies.
TABLE 10

REFUSE COLLECTION CASE STUDY OVERVIEW

\begin{tabular}{|c|c|c|c|c|}
\hline \multicolumn{5}{|c|}{ Solution } \\
\hline \multicolumn{5}{|c|}{ Charge-on-the-stop at depot } \\
\hline \multicolumn{5}{|c|}{30 minutes charging boost at $50 \mathrm{~kW}$ power transfer } \\
\hline \multicolumn{5}{|c|}{ B) 10 'top-up' charging points along the route } \\
\hline \multicolumn{5}{|c|}{3 minutes charging boost at $50 \mathrm{~kW}$ power transfer } \\
\hline \multicolumn{5}{|c|}{ " $\mathrm{gCO}_{2} / \mathrm{mile}$} \\
\hline \multirow{2}{*}{ Diesel 2016} & \multicolumn{2}{|c|}{ EFV 2030} & \multicolumn{2}{|c|}{ EFV 2040} \\
\hline & Min & $\operatorname{Max}$ & Min & $\operatorname{Max}$ \\
\hline 1600 & 360 & 520 & 120 & 200 \\
\hline
\end{tabular}

\section{CONCLUSIONS}

(i) It has been shown in the paper that deep decarbonisation of the national road freight system by electrification is feasible. It would require installation of a backbone charge-on-the-move network on the nation's motorways. This could be achieved with either overhead cables or Inductive Power Transfer.

(ii) A logistics concept was proposed that, in conjunction with current and likely future electrification technologies, could provide a framework for the electrification of most road freight operations. The proposed logistics concept is divided into four 'operations' which are the 'long-haul trunking', 'urban delivery', 'home delivery', and other 'auxiliary services' such as refuse collection functions within the area of municipalities. Different vehicles and charging mechanisms were suggested for each of these operations.

(iii) Three vehicle models were developed using an advanced vehicle simulator including electric Light Good Vehicles (LGVs), electric Heavy Good Vehicles up to 10 tonnes (HGV10), and electric Heavy Good Vehicles up to 38 tonnes gross mass (HGV38). The power requirement of each vehicle model was calculated over appropriate driving cycles. The outcomes were then combined with GB traffic data in order to set the baseline of the required power demand across GB. It was shown that an additional electrical load of 9.4GW would be added on the power demand during the peak hours of commuting due to the electrification of road freight transportation.

(iv) A charging simulation tool was developed to investigate the application of dynamic charging. The tool shows how various CoM layouts affect the SOC and the mileage range of the vehicle under investigation. The performance of the charging system was quantified by the 'Mean Effective Charging Rate'.

(v) Four case studies were developed for assessing the feasibility of electrification of road freight. It was shown that the shifting towards electric freight vehicles appears to be technically and financially feasible since large and expensive on-board batteries are not required. Significant reduction of $73 \% \mathrm{CO}_{2}$ emissions in average when compared with conventional freight vehicles could be achieved by 2030 for all case studies examined. Even higher reduction of $91 \% \mathrm{CO}_{2}$ emissions by 2040 is feasible provided the current projections for decarbonisation of the electricity grid are achieved.

\section{REFERENCES}

[1] DECC, "UK Greenhouse Gas Emissions," Department of Energy \& Climate Change, 2013. 
[2] DfT, "Carbon Pathways analysis: Informing Development of a Carbon Reduction Strategy for the Transport Sector," Department for Transport, 2008.

[3] A. M. C. Odhams, R. L. Roebuck, Y. J. Lee, S. W. Hunt, and D. Cebon, "Factors influencing the energy consumption of road freight transport," Proc. Inst. Mech. Eng. Part C J. Mech. Eng. Sci., vol. 224, no. 9, pp. 19952010, Sep. 2010.

[4] P. Greening, M. Piecyk, A. Palmer, and A. McKinnon, "An assessment of the potential for demand-side fuel savings in the Heavy Goods Vehicle (HGV) sector," Centre for Sustainable Road Freight Technical Report, 2015 .

[5] D. W. Keith and A. E. Farrell, "Rethinking Hydrogen Cars," Science., vol. 301, no. 5631, pp. 315-316, 2003.

[6] M. Ball and M. Wietschel, "The future of hydrogen - opportunities and challenges," Int. J. Hydrogen Energy, vol. 34, no. 2, pp. 615-627, 2009.

[7] U. Bossel, "Does a Hydrogen Economy Make Sense?," Proc. IEEE, vol. 94, no. 10, pp. 1826-1837, Oct. 2006.

[8] O. Sandru, "Why Hydrogen Cars are Less Efficient than Electrics," The Green Optimistic, 2015. [Online]. Available: http://www.greenoptimistic.com/hydrogen-cars-efficiency/\#.V_e7eArJpg.

[9] European Union, "Directive 2009/28/EC of the European Parliamanet and of the Council," 2009.

[10] W. J. Midgley and D. Cebon, "Evaluation of a fuel-efficient urban delivery vehicle," Proc. Inst. Mech. Eng. Part D J. Automob. Eng., Feb. 2017.

[11] W. J. Midgley and D. Cebon, "Comparison of regenerative braking technologies for heavy goods vehicles in urban environments," Proc. Inst. Mech. Eng. Part D J. Automob. Eng., vol. 226, no. 7, pp. 957-970, Mar. 2012.

[12] W. Midgley, H. Cathcart, and D. Cebon, "Modelling of hydraulic regenerative braking systems for heavy vehicles," Proc. Inst. Mech. Eng. Part D J. Automob. Eng., vol. 227, no. 7, pp. 1072-1084, Jan. 2013.

[13] M. Bruning and W. Schonewolf, "Freight transport system for urban shipment and delivery," in 2011 IEEE Forum on Integrated and Sustainable Transportation Systems, 2011, pp. 136-140.

[14] DECC, "Updated energy and emissions projections," Department of Energy \& Climate Change, 2015.

[15] ARUP, "Regent Street delivery and servicing reduction scheme," 2015. [Online]. Available:

http://www.arup.com/projects/regent_street_delivery_and_servicing_red uction_scheme.

[16] UPS, "Sustainability Report," 2015.

[17] AustriaTech, "Electric Fleets in Urban Logistics," 2014.

[18] S. Beggs, S. Cardell, and J. Hausman, "Assessing the potential demand for electric cars," J. Econom., vol. 17, no. 1, pp. 1-19, Sep. 1981.

[19] J. Reed, "Buyers loath to pay more for electric cars," Financial Times, 2010. [Online]. Available: http://www.ft.com/cms/s/0/acc0a646-c40511df-b827-00144feab49a.html\#axzz4GmVVbS5T.

[20] H. Sylvia, H. Omar, C. Thierry, and V. M. Joeri, "Social acceptance of wireless battery charging systems: Belgium case study," in 2014 IEEE International Electric Vehicle Conference (IEVC), 2014, pp. 1-6.

[21] S. J. Gerssen-Gondelach and A. P. C. Faaij, "Performance of batteries for electric vehicles on short and longer term," J. Power Sources, vol. 212, pp. 111-129, Aug. 2012.

[22] V. Etacheri, R. Marom, R. Elazari, G. Salitra, and D. Aurbach, "Challenges in the development of advanced Li-ion batteries: a review," Energy Environ. Sci., vol. 4, no. 9, p. 3243, Aug. 2011.

[23] T. M. Fisher, K. B. Farley, Y. Gao, H. Bai, and Z. T. H. Tse, "Electric vehicle wireless charging technology: a state-of-the-art review of magnetic coupling systems," Wirel. Power Transf., pp. 1-10, Sep. 2014.

[24] A. W. Kelley and W. R. Owens, "Connectorless power supply for an aircraft-passenger entertainment system," IEEE Trans. Power Electron., vol. 4, no. 3, pp. 348-354, Jul. 1989.

[25] B. J. Heeres, D. W. Novotny, D. M. Divan, and R. D. Lorenz, "Contactless underwater power delivery," in Proceedings of 1994 Power Electronics Specialist Conference - PESC'94, 1994, pp. 418-423.

[26] Jia Junlin, Liu Weigang, and Wang Haiqun, "Contactless power delivery system for the underground flat transit of mining," vol. 1. pp. 282-284 vol.1, 2003.

[27] B. Maisuria, "Inductive power transfer platform with smart pickup," New Zealand, 2011

[28] J. M. Barnard, J. A. Ferreira, and J. D. van Wyk, "Sliding transformers for linear contactless power delivery," IEEE Trans. Ind. Electron., vol. 44, no. 6, pp. 774-779, 1997.
[29] J. Boys and A. Green, "Intelligent road-studs-lighting the paths of the future," in IPENZ Annual Conference: Engineering, providing the foundations for society, 1996

[30] D. Nicolaides and J. Miles, "Wireless Electric Charge-On-The-Move: An Economic Appraisal of the Potential for the UK Transport Application," in International Conference on Transportation and Civil Engineering, 2015, pp. 53-59.

[31] D. Nicolaides, R. McMahon, D. Cebon, and J. Miles, "A national power infrastructure for Charge-on-the-Move," in IEEE PELS Workshop on Emerging Technologies: Wireless Power, 2016, pp. 180-185.

[32] D. Nicolaides and J. Miles, "Wireless Electric Charge-on-the-move: A sustainability appraisal of the potential for the UK transport application," J. Multidiscip. Eng. Sci. Technol., vol. 2, no. 8, pp. 2238-2246, 2015.

[33] M. Budhia, J. T. Boys, G. A. Covic, and C.-Y. Huang, "Development of a Single-Sided Flux Magnetic Coupler for Electric Vehicle IPT Charging Systems," IEEE Trans. Ind. Electron., vol. 60, no. 1, pp. 318-328, Jan. 2013.

[34] H. H. Wu, A. Gilchrist, K. D. Sealy, and D. Bronson, "A High Efficiency $5 \mathrm{~kW}$ Inductive Charger for EVs Using Dual Side Control," IEEE Trans. Ind. Informatics, vol. 8, no. 3, pp. 585-595, Aug. 2012.

[35] P. Ning, J. M. Miller, O. C. Onar, and C. P. White, "A compact wireless charging system for electric vehicles," in 2013 IEEE Energy Conversion Congress and Exposition, 2013, pp. 3629-3634.

[36] D. Naberezhnykh, N. Reed, F. Ognissanto, T. Theodoropoulos, and H. Bludszuweit, "Operational requirements for dynamic wireless power transfer systems for electric vehicles," in 2014 IEEE International Electric Vehicle Conference (IEVC), 2014, pp. 1-8.

[37] X. Zhang, Z. Yuan, Q. Yang, Y. Li, J. Zhu, and Y. Li, "Coil Design and Efficiency Analysis for Dynamic Wireless Charging System for Electric Vehicles," IEEE Trans. Magn., vol. 52, no. 7, pp. 1-4, Jul. 2016.

[38] N. Omar, M. A. Monem, Y. Firouz, J. Salminen, J. Smekens, O. Hegazy, H. Gaulous, G. Mulder, P. Van den Bossche, T. Coosemans, and J. Van Mierlo, "Lithium iron phosphate based battery - Assessment of the aging parameters and development of cycle life model," Appl. Energy, vol. 113, pp. 1575-1585, Jan. 2014.

[39] Milton Keynes Council, "Electric Bus," 2012. [Online]. Available: https://www.milton-keynes.gov.uk/streets-transport-and-parking/bustravel/bus-projects/electric-bus.

[40] H. G. Grunjes and M. Birkner, "Electro mobility for heavy duty vehicles (HDV): The Siemens eHighway System," in 12th International Symposium on Heavy Vehicle Transportation Technology, 2012.

[41] A. Brooker, K. Haraldsson, T. Hendricks, V. Johnson, K. Kenneth, B. Kramer, T. Markel, M. O'Keefe, S. Sprik, K. Wipke, and M. Zolot, "ADVISOR Advanced Vehicle Simulator," NREL, 2013. [Online]. Available: http://adv-vehicle-sim.sourceforge.net/.

[42] R. D. Senger, "Validation of ADVISOR as a Simulation Tool for a Series Hybrid Electric Vehicle Using the Virginia Tech FutureCar Lumina," Virginia Tech, 1997.

[43] K. B. Wipke, M. R. Cuddy, and S. D. Burch, "ADVISOR 2.1: a userfriendly advanced powertrain simulation using a combined backward/forward approach," IEEE Trans. Veh. Technol., vol. 48, no. 6, pp. 1751-1761, 1999.

[44] T. Barlow, S. Latham, I. McCrae, and P. Boulter, "A reference book of driving cycles for use in the measurement of road vehicle emissions," 2009.

[45] Department for Transport, "Traffic counts," 2014. [Online]. Available: http://www.dft.gov.uk/traffic-counts/index.php.

[46] Department for Transport, "Average annual daily flow and temporal traffic distributions," 2015.

[47] Royal Academy of Engineering, "GB electricity capacity margin," 2013.

[48] G. Ault, D. Frame, N. Hughes, and N. Strachan, "Electricity Network Scenarios for Great Britain in 2050," 2008.

[49] ENSG, "Our Electricity Transmission Network: A vision for 2020," 2012.

[50] UK Power Networks, "Business plan (2015 to 2023)," 2012.

[51] Northwest Electricity, "Strategic Direction Statement," 2013.

[52] EIA, "How much carbon dioxide is produced by burning gasoline and diesel fuel?," 2016. [Online]. Available: http://www.eia.gov/tools/faqs/faq.cfm?id=307\&t=11.

[53] C. Botsford and A. Szczepanek, "Fast Charging vs. Slow charging: Pros and cons for the New Age of Electric Vehicles," in International Battery, Hybrid and Fuel Cell Electric Vehicle Symposium, 2009.

[54] Department for Transport, "Guidance on Road Classification and the Primary Route network," 2012. 